\title{
Perception of the Educational Environment and Its Correlation with Academic Performance of Medical Students in a Public Sector Medical Institute of Pakistan
}

\author{
Mehwish Kaneez ${ }^{1 *}$, Syed Muhammad Jawad Zaidi ${ }^{1}$, Hamza Waqar Bhatti ${ }^{1}$, Hania \\ Ijaz $^{1}$, Mishal Fatima ${ }^{1}$, Muhammad Hamza ${ }^{1}$ \\ ${ }^{1}$ Rawalpindi Medical University, Rawalpindi, Pakistan \\ *Corresponding author. Email: mehwish.kaneez@gmail.com
}

\begin{abstract}
Objective: The study aims to assess their correlation and provide recommendations for a conducive educational environment (EE).

Methods: This was a cross-sectional study conducted in a public sector medical institute of Pakistan in which EE of 320 students from $2^{\text {nd }}$ till $5^{\text {th }}$ years was assessed using Dundee Ready Educational Environment Measure (DREEM).

Results: The mean DREEM score was 98.32/200 indicating the perception to be on the less positive side. Students' academic self-perception (SASP) domain scored highest $(16.97 / 32,53 \%)$ while students' perception of teaching (SPT) domain scored the lowest $(20.07 / 44,45.5 \%)$. The difference in mean DREEM and subdomains scores across academic years were statistically significant $(\mathrm{p}<0.001)$ with $2^{\text {nd }}$-year having the lowest $(86.4)$ and $4^{\text {th }}$ year having the highest (110.22) mean scores. There was a significant positive correlation between academic performance and total DREEM score $(\mathrm{r}=0.661, \mathrm{p}<0.01)$ The simple linear regression for predicting obtained scores in recent professional exams by total DREEM score was statistically significant $(\mathrm{p}<0.001)$.

Conclusion: Academic performance was strongly correlated with the perception of the educational environment. Improving the perception of the educational environment will lead to better academic performance. Interventions such as training of teaching faculty, promotion of research-oriented learning, and the establishment of a support system for stressed students will help the administration to provide a better educational environment and improve the academic performance of students.
\end{abstract}

Keywords: Educational Environment, DREEM, Perception.

\section{INTRODUCTION}

The opinion of students regarding the curriculum, physical attributes, social perspectives, and psychological aspects of their surroundings constitutes the perception of their educational environment [1]. This perception may determine students' behavior and approach towards their course that may affect their academic capabilities [2]. A positive educational environment is necessary for grooming and motivating the students of all disciplines. However, it has proven to be a very important factor in shaping medical students as future budding doctors [3]. The kind of educational environment provided to them is very crucial as they will be providing medical treatment to patients in the future $[1,3]$. A conducive educational environment can lead to a positive perception that may show a constructive effect on the cognitive abilities of medical students enabling them to become keen learners and competent clinicians [4]. On the other hand, an unfavorable educational environment is a cause of demotivation, low self-esteem, and poor academic performance which can hinder their growth as doctors [5]. Therefore, medical students should be provided with a positive educational environment achieving optimal learning outcomes $[2,3,5]$.

Multiple dynamic factors can influence the educational environment which makes the determinant difficult to evaluate quantitatively [6]. However, the Dundee Ready Education Environment Measure (DREEM) has been internationally validated and proven to be a reliable assessment tool for measuring the educational environment. [2,6]. DREEM assesses the educational environment in five dimensions including Students' Perception of Learning, Students' Perception of Teachers, Students' Academic Self-perceptions, Students' Perception of Atmosphere, and Students' Social Self-perceptions [3,4]. Previous statistics have shown that the mean DREEM scores for developing countries like India (101.13) and Nigeria (101.82) were less positive as compared to some highly developed countries like Germany (140) and Australia (137.3) [7- 
10]. Many kinds of researches have been conducted to assess the educational environment in different study settings. However, only a limited number of studies predicted or correlated academic performance with the DREEM scores [11,12].

Modernization of the medical curriculum and wide diversification of medical students necessitates the need for timely evaluation of the educational environment [13]. The dilemma is that the faculty does not consider students' perspectives of the educational environment despite its marked influence on the students' academic performance $[11,12]$. The condition is even worse in the public sector institutes of developing countries where its true status is still not regularly assessed. Can DREEM scores predict Academic performance? The ambiguity surrounding the effect of the educational environment on the academic performance of medical students demands the need for this study.

Thus, the study aims to assess the perception of the educational environment, its relation, and its effects on academic performance among students of a public sector institute of a developing country. The researchers also aim to provide potential recommendations for rectification of problematic areas in an educational environment as identified by the DREEM scale.

\section{METHODS}

This cross-sectional study was conducted in at Rawalpindi Medical University, Rawalpindi, Pakistan from December 2019 to February 2020. In the institution, the MBBS course is divided into five academic years and education is divided into two phases. The preclinical phase includes the 1 st and 2nd year while the clinical phase includes students from 3rd, 4th, and 5th-year. The university has a total of 1500 students and sample size was calculated using WHO sample size calculator. A stratified random sampling technique was used to collect data from 320 students (80 students from each academic year) of the 2nd to 5th-year MBBS. Only those students were included in the study who had completed at least one academic year in the institution. Keeping in mind the inclusion criteria, the students of first-year MBBS were excluded from the study as they were yet to complete their academic year. The purpose of the study was explained properly to the students and consent was taken. The scores obtained by students in the recent professional examinations held by the university were collected from the department of medical education after permission. These scores were converted to percentages for analysis.

The internationally validated English version of DREEM (Dundee Ready Educational Environment Measure) was given to students for an assessment of their educational environment [4]. DREEM survey includes 50 items and each is scored on a 5-Point Likert scale ranging from strongly agree to strongly disagree. The scores for positive attributes are 4 for strongly agree, 3 for agree, 2 for neutral, 1 for disagree and 0 for strongly disagree while nine negative items (Items 4, 8, 9, 17, 25, $35,39,48$ and 50) are reverse scored $[4,6]$.

Items with mean score $\geq 3.5$ are considered truly positive, scores between 2-3.5 show areas going in the right direction but need improvement while mean scores of $\leq 2$ are considered problematic [5,14].

The items are classified into 5 subscales based on students' perception:

a) Students' Perception of Learning (SPL) - 12 items; maximum score is 48 .

b) Students' Perception of Teachers (SPT) - 11 items; maximum score is 44 .

c) Students' Academic Self-Perceptions (SASP) - 8 items; maximum score is 32 .

d) Students' Perception of Atmosphere (SPA) - 12 items; maximum score is 48 .

e) Students' Social Self-Perceptions (SSSP) - 7 items; maximum score is 28 .

The total score of the questionnaire is 200 . Score $<50$ is considered 'very poor'; a score between 50-100 is rated as 'many problems'; a score between $100-150$ is considered 'more positive than negative'; score $>150$ is rated as 'excellent' [14].

Data were analyzed using IBM Statistical Package for Social Sciences (SPSS), version 25 (IBM Corp., Armonk, NY, USA). Descriptive statistics were applied and means and standard deviations were tabulated for total and subscale scores. Cronbach's alpha value for the scale was calculated. One-way analysis of variance (ANOVA) along with Tukey posthoc analysis was used to evaluate the difference in DREEM scores across academic years. The Pearson's correlation was used to correlate the academic performance (measured by percentages obtained in recent professional examination) with total DREEM and subdomain scores. The simple linear regression was applied to predict the exam scores by total DREEM and subdomain scores. P-value of less than 0.05 was considered statistically significant.

\section{RESULTS}

The DREEM scale showed good reliability with Cronbach's alpha value of 0.873 . The Cronbach alpha values of SPL, SPT, SASP, SPA, and SSSP were 0.79, $0.76,0.71,0.74$ and 0.69 respectively. A total of 320 medical students from 2nd to 5th-year MBBS participated in the study. Table 1 shows the details of the students 
Table-1: details of study participants (stratified random sampling was used)

\begin{tabular}{|c|c|c|c|c|c|}
\hline Variable & $\begin{array}{l}2^{\text {nd }} \text { year } \\
(n=80)\end{array}$ & $\begin{array}{l}3^{\text {rd }} \text { year } \\
(n=80)\end{array}$ & $\begin{array}{l}4^{\text {th }} \text { year } \\
(n=80)\end{array}$ & $\begin{array}{l}5^{\text {th }} \text { year } \\
(n=80)\end{array}$ & $\begin{array}{c}\text { Total } \\
(\mathrm{n}=320)\end{array}$ \\
\hline \multicolumn{6}{|l|}{ Age } \\
\hline $17-19$ years & 18 & 0 & 0 & 0 & 18 \\
\hline $20-23$ years & 62 & 80 & 80 & 70 & 292 \\
\hline Greater than 23 years & 0 & 0 & 0 & 10 & 10 \\
\hline \multicolumn{6}{|l|}{ Gender } \\
\hline Male & 47 & 38 & 38 & 43 & 166 \\
\hline Female & 33 & 42 & 42 & 37 & 154 \\
\hline \multicolumn{6}{|l|}{$\begin{array}{l}\text { Percentages obtained in previous } \\
\text { Prof. Examination }\end{array}$} \\
\hline $50-59.9 \%$ & 16 & 13 & 2 & 7 & 38 \\
\hline $60-69.9 \%$ & 33 & 35 & 30 & 49 & 147 \\
\hline $70-79.9 \%$ & 30 & 32 & 41 & 20 & 123 \\
\hline$>80 \%$ & 1 & 0 & 7 & 4 & 12 \\
\hline
\end{tabular}

One-way Analysis of variance (ANOVA), showed that the difference in mean scores across academic years was statistically significant ( $\mathrm{p}$ valve $<0.001$ ). Post hoc analysis revealed significant differences between 2 nd (pre-clinical) year having low mean scores and 3rd, 4th, and 5th (clinical) years having high mean scores as illustrated in Table 2.

Table-2: Comparison of mean DREEM scores across academic years

\begin{tabular}{|c|c|c|c|c|c|c|}
\hline $\begin{array}{l}\text { DREEM domains } \\
\text { (max. score) }\end{array}$ & $\begin{array}{l}2^{\text {nd }} \text { year } \\
\text { means }\end{array}$ & $\begin{array}{l}3^{\text {rd }} \text { year } \\
\text { means }\end{array}$ & $\begin{array}{l}4^{\text {th }} \text { year } \\
\text { means }\end{array}$ & $\begin{array}{l}5^{\text {th }} \text { year } \\
\text { means }\end{array}$ & $\begin{array}{c}\mathrm{p}- \\
\text { values } *\end{array}$ & Post-hoc** \\
\hline SPL (48) & $19.66 \pm 6.10$ & $18.1 \pm 5.70$ & $26.4 \pm 6.8$ & $26.4 \pm 6.1$ & $<0.001$ & $\begin{array}{c}2: 4,2: 5,3: 4, \\
3: 5\end{array}$ \\
\hline SPT (44) & $17.25 \pm 5.78$ & $17.7 \pm 4.00$ & $21.88 \pm 4.8$ & $23.4 \pm 3.6$ & $<0.001$ & $\begin{array}{c}2: 4,2: 5,3: 4, \\
3: 5\end{array}$ \\
\hline SASP (32) & $14.76 \pm 5.11$ & $15.5 \pm 3.4$ & $19.25 \pm 3.64$ & $18.37 \pm 5.13$ & $<0.001$ & $\begin{array}{c}2: 4,2: 5,3: 4, \\
3: 5\end{array}$ \\
\hline SPA (48) & $22.4 \pm 7.55$ & $23.5 \pm 5.08$ & $28.5 \pm 6.12$ & $27.18 \pm 4.46$ & $<0.001$ & $\begin{array}{c}2: 4,2: 5 \\
3: 4,3: 5\end{array}$ \\
\hline SSSP (28) & $12.36 \pm 3.86$ & $12.5 \pm 3.55$ & $14.08 \pm 3.10$ & $14.30 \pm 4.12$ & $<0.001$ & $2: 5,3: 5$ \\
\hline Total (200) & $86.4 \pm 21.5$ & $87.3 \pm 15.6$ & $110.22 \pm 17.4$ & $109.33 \pm 17.15$ & $<0.001$ & $\begin{array}{c}2: 4,2: 5,3: 4, \\
3: 5\end{array}$ \\
\hline
\end{tabular}

The mean DREEM score of all participants was $98.32 \pm 21.33$. The highest scores were recorded for SASP $(16.97 / 32,53 \%)$ and SPA domains $(25.39 / 48,52.8 \%)$ followed by SSSP $(13.31 / 28,47.5 \%)$, SPL (22.63/48, $47.1 \%)$ and finally SPT $(20.07 / 44,45.6 \%)$. Total
DREEM and subdomain scores had a strong significant positive correlation with obtained percentages in recent professional examination (except for SSSP which showed moderate significant correlation). Pearson's $r$ and $\mathrm{p}$ values are shown in Table 3 .

Table-3: Correlation of obtained Examination scores (in percentages) with DREEM scores.

\begin{tabular}{|c|c|c|c|}
\hline Parameter & Means & r-values* & p-values \\
\hline Obtained percentages in previous professional exams & $68.06 \pm 6.86$ & 1 & \\
\hline Students' perception of learning (SPL) & $22.63 \pm 7.31$ & 0.528 & $<0.01$ \\
\hline Students' perception of teachers (SPT) & $20.07 \pm 5.37$ & 0.501 & $<0.01$ \\
\hline Students' academic self-perception (SASP) & $16.97 \pm 4.79$ & 0.508 & $<0.01$ \\
\hline
\end{tabular}


Students' perception of atmosphere (SPA)

Students' social self-perception (SSSP)

Total DREEM score

$\begin{array}{ccc}25.39 \pm 6.37 & 0.578 & <0.01 \\ 13.31 \pm 3.7 & 0.346 & <0.01 \\ 98.32 \pm 21.33 & 0.661 & <0.01\end{array}$

*Pearson correlation

Simple linear regression analysis revealed that the model explained $43.7 \%$ of the variance and that the model was significant, $F(1,318)=246.51$, $p<0.001$. It was found that DREEM scores significantly predicted academic performance among medical students $(p<0.001)$. The final predictive equation is illustrated in Table 4.

Table-4 Simple linear regression for predicting previous professional exam percentages with total DREEM and subdomain scores.

\begin{tabular}{cccccc}
\hline Dependent Variables & $\mathrm{R}^{2}$ & $\begin{array}{c}\text { Unstandardized } \\
\text { Beta (B) }\end{array}$ & Constant & $\begin{array}{c}\text { 95\% Confidence } \\
\text { Intervals for B }\end{array}$ & P-value \\
\hline Total DREEM score & 0.437 & 0.213 & 47.15 & $0.186-0.239$ & $<0.001$ \\
SPL & 0.279 & 0.496 & 56.849 & $0.408-0.584$ & $<0.001$ \\
SPT & 0.251 & 0.641 & 55.198 & $0.519-0.763$ & $<0.001$ \\
SASP & 0.258 & 0.727 & 55.725 & $0.591-0.863$ & $<0.001$ \\
SPA & 0.334 & 0.622 & 52.257 & $0.526-0.719$ & $<0.001$ \\
SSSP & 0.120 & 0.630 & 59.679 & $0.442-0.818$ & 0.001
\end{tabular}

Estimated obtained percentage $=47.15+\{0.213 \times($ total DREEM score $)\}$.

It was noted that none of the individual items on the scale had mean scores above 3.5. Twenty-six out of fifty items had mean scores below 2. The lowest scoring items included 3 (There is a good support system for students who get stressed), 6 (The teachers deliver research-led teaching), and item 13 (The teaching is student-centered) with scores of $0.8,1.4$, and 1.5 respectively. The mean scores of items with mean scores below 2 are tabulated in Table 5.

Table-5: Problematic areas in educational environment (items with mean scores below 2)

\begin{tabular}{|c|c|c|c|}
\hline $\begin{array}{l}\text { Item } \\
\text { No. }\end{array}$ & Question & $\begin{array}{l}\text { Mean } \\
\text { score }\end{array}$ & $\begin{array}{l}\text { Standard } \\
\text { deviation }\end{array}$ \\
\hline \multicolumn{4}{|c|}{ Domain: Student perception in learning } \\
\hline 1. & I am encouraged to participate in the class & 1.9 & 1.2 \\
\hline 7. & The teaching is often stimulating & 1.9 & 1.0 \\
\hline 13. & The teaching is student-centered & 1.5 & 0.9 \\
\hline 16. & The teaching helps to develop my competence & 1.9 & 1.1 \\
\hline 22. & The teaching helps to develop my confidence & 1.8 & 1.0 \\
\hline 24. & The teaching time is put to good use & 1.9 & 1.1 \\
\hline 25. & The teaching over-emphasizes factual learning & 1.8 & 0.9 \\
\hline 44. & The teaching encourages me to be an active learner & 1.8 & 1.0 \\
\hline 47. & Long term learning is emphasized over short-term learning & 1.9 & 1.2 \\
\hline 48. & The teaching is too teacher-centered & 1.7 & 1.1 \\
\hline \multicolumn{4}{|c|}{ Domain: Students' perception of teachers } \\
\hline 6. & The teachers deliver research-led teaching & 1.4 & 0.9 \\
\hline 8. & The teachers ridicule the students & 1.9 & 1.2 \\
\hline 9. & The teachers are authoritarian & 1.8 & 1.0 \\
\hline 18. & The teachers help me to develop my practical skills & 1.8 & 1.0 \\
\hline 29. & The teachers are good at providing feedback to students & 1.7 & 1.2 \\
\hline
\end{tabular}


32. The teachers provide constructive criticism here

39. The teachers get angry in class

50. The students irritate the teachers

Domain: Students' academic self-perception

27. I can memorize all I need

31. I have learned a lot about the way scientific research is carried out Domain: Students' perception of the atmosphere

30. There are opportunities for me to develop my interpersonal skills

42. The enjoyment outweighs the stress of the course

49. I feel able to ask the questions I want

Domain: Students' social self-perceptions

3. There is a good support system for students who get stressed

4. I am too tired to enjoy the course

14. I am rarely bored on this course
$1.6 \quad 1.1$

$1.6 \quad 0.9$

$1.5 \quad 1.0$

$1.8 \quad 1.1$

$1.7 \quad 1.2$

$1.9 \quad 1.2$

$1.8 \quad 1.2$

$1.7 \quad 1.1$

$0.8 \quad 0.8$

$1.9 \quad 1.3$

$1.7 \quad 1.3$

\section{DISSCUSSION}

The mean DREEM score of all students revealed that students perceived their educational environment with 'many problems'. Past statistics have shown that high DREEM scores illustrate conducive and productive curricula while lower DREEM scores indicate a problematic and inefficient learning environment [7-10]. Certainly, the mean scores of the present study suggest that there are many weak areas which demand rapid evaluation for quality improvement so that an advantageous educational environment can be provided to our undergraduates. Studies conducted in developing countries like Nigeria and India yielded mean DREEM scores of 101.82 , and 101.13 respectively which are approximal to our study $[7,8]$. Studies conducted in developed countries yielded scores between 120-150 inferring that students were very much satisfied with their educational environment $[9,10]$. This discrepancy of mean DREEM scores studies of developed countries and that of our study demands the need for reforms in medical education for a more positive perception of the educational environment among our students.

In our study, the SPA domain was recorded to be 25.39/48 (52.8\%). According to the DREEM scoring guideline, it suggests that the students are perceiving their atmosphere more positively [15]. However, the low score of the SPT domain $(20.02 / 44,45.5 \%)$ necessitates the need for reforms in the teaching methodologies. The score for the SASP domain was 16.97/32 (53\%) which is on the border-line of the more positive side. The studies in developed countries show higher mean perception scores in all domains which are contrary to our study $[9,10]$. The developed countries have a more structured curriculum for their students which illustrates that the implementation of an outcome-based curriculum, student-centered approaches, and better teaching methodologies can improve perception scores $[9,10,16]$.

Our study showed a significant positive correlation between the DREEM scores and academic performance (measured by percentages obtained in recent professional examination) indicating that increasing the perception of the educational environment will increase the academic performance of students. A multicentric study conducted in Saudia Arabia also showed similar findings inferring a significant positive correlation of obtained GPA with mean DREEM and subdomain scores [11]. Another study in Sudan showed that the mean DREEM and subdomain scores were significantly higher in high academic achievers than low academic achievers [17]. This implies that the academic performance of students improves with a positive perception of the educational environment. Therefore, the provision of a more conducive educational environment can improve the academic performance of students.

To improve the educational environment and thus the academic performance of students, there is a need for rectification of problematic areas as identified by the DREEM scale. The conventional ways of teaching, less practical approach by the faculty and authoritative nature of the teachers were a few problematic areas that led to poor perception scores. Various studies conducted in developing countries also identified similar barriers to the poor perception of the educational environment $[7,8,17]$. Students also reported that there was a lack of support system for stressed students (item no 3 on DREEM scale). A study conducted in Saudi Arabia also reports a similar finding recommending the establishment of a support system for stressed students for their social comfort and academic excellence [13]. Similarly, a study concluded that high-stress levels were associated with poor academic performance among medical students [18]. The establishment of a stress management center in the institution will not only improve the educational climate of the institution but will also allow the students to concentrate on their studies more effectively to improve their academic performance. The low mean score in item number 6 (teachers deliver research-based lectures) indicates that immediate reforms must be made in promoting research-based learning not only among the students but also among the faculty. Moreover, the low score in item no. 13 (teaching is student-centered) and item no 48 (The teaching is too teacher-centered) suggest the need for implementation of student-centered teaching methodology with an integrated outcome-based 
curriculum to improve the perception of medical students.

The study also revealed that there was a significant difference in mean scores of preclinical (2nd) year and clinical (3rd, 4th, and 5th) years. The perception was more positive among the clinical students which indicated that learning techniques and teaching environment is better for clinical years as compared to pre-clinical years. An analysis reported in South Korea illustrates similar findings with a more positive perception of the educational environment among clinical years [16]. The proper clinical orientation given by the clinical faculty may be a reason for better perception scores among clinical students. Proper training of pre-clinical teachers by the clinical faculty for improving the quality of the educational environment may improve the perception among pre-clinical students.

The results of our study identified potential target areas that can assist in the provision of a better educational environment for students. Teacher centered teaching, lack of research orientation, having no support group for stressed students, and poor learning techniques employed by the faculty are a few reasons for low perception scores. However, a better perception of the educational environment can be achieved by making radical interventions. Delivery of focused studentcentered teaching, friendly student-teacher interaction, and a proper and timely evaluation of students in terms of constructive feedback will aid in achieving a more conducive educational environment. After these interventions, the DREEM scale can be applied again and present data can help as a baseline for comparison with the new data (collected after interventions) to assess for improvement in the educational environment and academic performance of students.

One of the limitations was that we only investigated and reported a fixed set of factors that are present in the DREEM questionnaire while much of the other qualitative factors that may influence an educational environment such as culture, demographics, and personality were not reported. Therefore, the addition of qualitative elements such as structured interviews would have made the results more comprehensive as most aspects would have been covered. Despite the limitation, the study has identified potential target areas for improving the educational environment in a public sector institute of a developing country. The educational environment is an ever-changing determinant and more studies of such kind should be conducted regularly to determine the strengths and weaknesses of the curriculum that will help to improve the quality of medical education and academic performance of students in a developing country.

\section{CONCLUSION}

To conclude, students perceived their educational environment less positively indicating many problem areas. The students of clinical years $(3 \mathrm{rd}, 4 \mathrm{th}$, and 5 th years) perceived the educational environment is more positive than the preclinical year (2nd year). The academic performance of students is strongly correlated and can be predicted with DREEM scores (improves by increasing DREEM scores). Interventions such as training of faculty, effective feedback delivery, promotion of research-oriented learning, and the establishment of a support system for stressed students will aid in achieving a better educational environment for the students that will ultimately improve their academic performance.

\section{AUTHORS' CONTRIBUTIONS}

Conceptualization: MK, HWB. Data curation: SMJZ MK, HWB. Formal analysis: SMJZ, HWB. Methodology: MH, HI. Project administration: HWB Visualization: MH, MF. Writing: MK SMJZ HI. Review: $\mathrm{MH}, \mathrm{MF}$

\section{REFERENCES}

[1] Skochelak SE, Stansfield RB, Dunham L, Dekhtyar M, Gruppen LD, Christianson C, Filstead W, Quirk M. Medical student perceptions of the learning environment at the end of the first year: A 28medical school collaborative. Acad Med. 2016;91(9):1257-62.

[2] Amaranathan A, Dharanipragada K, Lakshminarayanan S. Medical students' perception of the educational environment in a tertiary care teaching hospital in india. Natl Med J India. 2018;31(4):231-6.

[3] Shehnaz SI, Sreedharan J. Students' perceptions of educational environment in a medical school experiencing curricular transition in United Arab Emirates. Med Teach. 2011;33(1).

[4] Bakhshialiabad H, Bakhshi G, Hashemi Z, Bakhshi A, Abazari F. Improving students' learning environment by DREEM: An educational experiment in an Iranian medical sciences university (2011-2016). BMC Med Educ. 2019;19(1):1-10.

[5] Veerapen K, McAleer S. Students' perception of the learning environment in a distributed medical programme. Med Educ Online. 2010;15.

[6] Sengupta P, Sharma A, Das N. Perception of learning environment among undergraduate medical students in two different medical schools through DREEM and JHLES questionnaire. $J$ Clin Diagnostic Res. 2017;11(2):JC01-4.

[7] Kohli V, Dhaliwal U. Medical students' perception of the educational environment in a medical college in India: a cross-sectional study using the Dundee Ready Education Environment questionnaire. J Educ Eval Health Prof. 2013 Jun;10:5. 
[8] Okoye O, Ezisi CN, Ezepue FU. Evaluation of the learning and teaching environment of the Faculty of Medical Sciences, College of Medicine, University of Nigeria, Enugu Campus. Niger J Clin Pract. 2017 Aug;20(8):958-63.

[9] Kavukcu E, Burgazli KM, Akdeniz M, Bilgili P, Öner M, Koparan S, Yörümez A. Family Medicine and Sports Medicine Students' Perceptions of Their Educational Environment at a Primary Health Care Center in Germany: Using the DREEM Questionnaire. Postgrad Med. 2012 Sep;124(5):143-50.

[10] Brown T, Williams B, Lynch M. The Australian DREEM: evaluating student perceptions of academic learning environments within eight health science courses. Int J Med Educ. 2011;2:94-101.

[11] Nouh T, Anil S, Alanazi A, Al-Shehri W, Alfaisal $\mathrm{N}$, Alfaris B, Alamer E. Assessing correlation between students' perception of the learning environment and their academic performance. J Pak Med Assoc. 2016;66(12):1616-20.

[12] Sarwar S, Tarique S. Perception of educational environment: Does it impact academic performance of medical students? J Pak Med Assoc. 2016;66(10):1210-4.

[13] Altemani AH, Merghani TH. The quality of the educational environment in a medical college in Saudi Arabia. Int J Med Educ. 2017;8:128-32.

[14] Patil AA, Chaudhari VL. Students' perception of the educational environment in medical college: a study based on DREEM questionnaire. Korean $\mathrm{J}$ Med Educ. 2016;28(3):281-8.

[15] Noreen K, Khan KA, Nehra RA. Students' Perception of Learning Environment Using Dundee Ready Education Environment Measure (Dreem) Inventory. Pakistan J Public Heal. 2018;8(2):112-6.

[16] Ahn YJ, Hu W. Evaluation of the Educational Environment at a Graduate Medical School in South Korea using the DREEM Questionnaire. MedEdPublish. 2019;8(2).

[17] Ahmed Y, Taha MH, Al-Neel S, Gaffar AM. Students' perception of the learning environment and its relation to their study year and performance in Sudan. Int J Med Educ. 2018;9:145-50.

[18] Sohail N. Stress and academic performance among medical students. J Coll Physicians Surg Pak. 2013 Jan;23(1):67-71. 